\title{
Acinetobacter johnsonii
}

National Cancer Institute

\section{Source}

National Cancer Institute. Acinetobacter johnsonii. NCI Thesaurus. Code C86093.

A species of aerobic, Gram negative, rod shaped bacteria assigned to the phylum

Proteobacteria. This bacteria is nonmotile, oxidase negative, nonhemolytic and does not

reduce nitrates. A. johnsonii is a commensal organism on human skin and oropharynx but may be a cause of nosocomial infections. 